\title{
GMR
}

\section{Physical and chemical characteristics of pitaya fruits at physiological maturity}

\author{
T.A. Ortiz and L.S.A. Takahashi \\ Departamento de Agronomia, Centro de Ciências Agrárias, \\ Universidade Estadual de Londrina, Londrina, PR, Brasil \\ Corresponding author: T.A. Ortiz \\ E-mail: thiago.ortiz@hotmail.com
}

Genet. Mol. Res. 14 (4): 14422-14439 (2015)

Received January 21, 2015

Accepted May 28, 2015

Published November 18, 2015

DOI http://dx.doi.org/10.4238/2015.November.18.5

\begin{abstract}
The aim of this study was to analyze the physical and chemical characteristics of the maturation process of pitaya fruit (Hylocereus undatus) to identify indicators that can be used to determine the point of physiological maturity and establish the optimal timing of physiological maturity for harvesting the fruit. A completely randomized experimental design was employed and four biological repeats were performed. Physiological maturity was assessed using various physical characteristics: longitudinal length (LL), equatorial diameter (ED), pericarp thickness (PeT), pulp thickness (PuT), fruit mass (FM), pulp mass (PuM), pericarp mass (PeM), pericarp percentage $(\% \mathrm{Pe})$, pulp percentage $(\% \mathrm{Pu})$, pulp/pericarp ratio $(\mathrm{Pu} / \mathrm{Pe})$, pericarp color index $(\mathrm{CI})$, hue color angle $\left(h^{\circ}\right)$, lightness index $\left(L^{*}\right)$, chroma $\left(C^{*}\right)$, blue-yellow variation $\left(b^{*}\right)$, and green-red variation $\left(a^{*}\right)$. Additionally, chemical characteristics such as soluble solid content (SS), titratable acidity (TA), SS/TA ratio, and $\mathrm{pH}$ were screened. The data were statistically analyzed by fitting regression models and computing Pearson's correlation coefficients $(\mathrm{P}<0.05)$. Physiological maturity in pitaya fruits occurred between the 30th and 32nd days after anthesis, and this proved to be the optimal period for harvest. At this time, the fruit was completely red with high SS, and had the recommended
\end{abstract}


values of TA, $\mathrm{pH}$, and SS/TA ratio. During this period, ED, PuT, FM, $\mathrm{PuM}, \% \mathrm{Pu}$, and $\mathrm{Pu} / \mathrm{Pe}$ increased while $\mathrm{PeT}, \mathrm{PeM}$, and \%Pe fell; these changes are considered desirable by producers and/or consumers. PuM was the variable that displayed more strong's association with other variables in the analysis.

Key words: Cactaceae; Days after anthesis; Hylocereus undatus; Fruit quality; Maturation; Phenological stage

\section{INTRODUCTION}

Pitaya species belong to the plant family Cactaceae that are found in the tropical and subtropical Americas, particularly in semi-desert areas of the hot regions of Latin America (Le Bellec et al., 2006). Hylocereus undatus (Haworth) Britton \& Rose is the most widely cultivated species and is grown for its fruit, which is red with white pulp (Nerd et al., 2002).

Pitaya fruit has traditionally been consumed in Colombia, Mexico, Nicaragua, and Vietnam; however, its niche in the exotic fruit market has grown in recent years (Le Bellec et al., 2006). In Brazil, consumer demand for the fruit has increased because of its organoleptic characteristics and nutraceutical properties (Silva et al., 2006; Andrade et al., 2008). Consequently, fruit producers have become increasingly interested in cultivating this specie because of the increased demand and aggregate market value of the pitaya fruit (Bastos et al., 2006).

The stage of maturation of fruit at harvest affects post-harvest development and influences the final quality. Fruit that has been harvested prematurely is susceptible to physiological disorders caused by cellular disorganization, and to the rupture of cell walls; however, fruit harvested when overripe is likely to show senescence, causing quantitative and qualitative losses (Chitarra and Chitarra, 2005).

The production of Cactaceae fruits depends on both intrinsic and extrinsic factors, as well as their interaction. Moreover, the organoleptic and nutritional quality of the fruit depends on the degree of maturation (Centurion Yah et al., 1999, 2000; Vázquez-Sánchez et al., 2005). Identifying the optimal timing of harvest requires an understanding of growth and developmental patterns from flowering, in order to establish maturation rates (Castro et al., 2008).

The maturation rates and post-harvest behavior of pitaya fruits, or their quality parameters are relatively unknown (Corrales García, 2003). However, certain features are considered important at harvest, such as pericarp color, which is considered an indicator of maturity. Additionally, the criteria soluble solid content, acidity, and number of days after anthesis (DAA) until the fruit is fully developed are often used to determine the timing of harvest (Nerd et al., 1999).

Fruit maturation is one of the least described events in plant phenology models (Chuine et al., 2003). Thus, determining the period in which fruit reaches physiological maturity is significant for the optimization of fruit harvest and quality. The aim of this study was to analyze the physical and chemical characteristics of the maturation process of pitaya fruit ( $H$. undatus) to identify indicators that can be used to determine the point of physiological maturity and establish the optimal timing of physiological maturity for harvesting the fruit. 


\section{MATERIAL AND METHODS}

The study was conducted between January and February 2012 in the Londrina State University (Universidade Estadual de Londrina - UEL), in northern State of Paraná, Brazil. The fruits were obtained from $H$. undatus plants that were approximately 10 years old and had been cultivated in the experimental area of the UEL Department of Agronomy, which is located at $23^{\circ} 23^{\prime} \mathrm{S}$ and $51^{\circ} 11^{\prime} \mathrm{W}$ at an average elevation of $566 \mathrm{~m}$. The soil is classified as Eutroferric Red Nitosol (according to the Brazilian soil classification system; Embrapa, 2013), and the plants were spaced $2.0 \times 3.0 \mathrm{~m}$ apart and supported by $2.5 \mathrm{~m}$ high trellises, with each trellis supporting two plants.

Flowers at anthesis were manually pollinated at night. Harvesting of fruit began 21 days later and lasted 12 days, with 4 fruits harvested per day. The experimental design was completely randomized, and four replicate experiments were performed.

Data on maximum/minimum temperatures and rainfall were recorded throughout the entire experimental period using an HT-500 ${ }^{\circledR}$ Datalogger (Instrutherm, São Paulo, Brazil) installed in the experimental area (Figure 1).

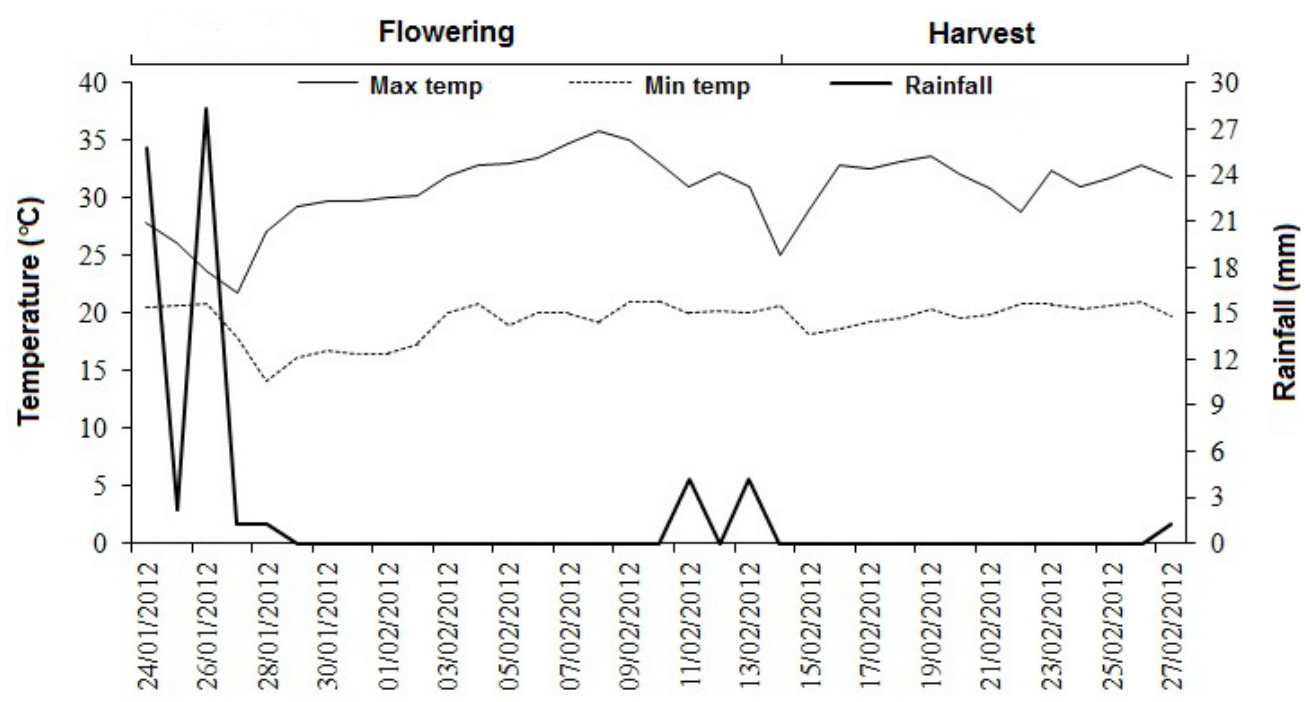

Figure 1. Daily minimum and maximum temperatures and rainfall in the period between flowering and harvest of pitaya fruits.

The fruits at each sampling point were harvested in the morning and sent immediately to the UEL Fruit Analysis Laboratory to measure their physical and chemical characteristics.

The following physical characteristics were determined using an analog caliper and recorded in cm: longitudinal length (LL), equatorial diameter (ED) of the fruit without scales, pericarp thickness (PeT), and pulp thickness (PuT). The fresh mass of the fruit (FM), its pulp $(\mathrm{PuM})$, and pericarp (PeM) were measured with a precision scale and recorded in $\mathrm{g}$. Based on these measurements, the pulp percentage $(\% \mathrm{Pu})$, pericarp percentage $(\% \mathrm{Pe})$, and ratio between pulp and pericarp masses $(\mathrm{Pu} / \mathrm{Pe})$ were calculated. 
The fruit color was determined by reflectometry using a CR-10 ${ }^{\circledR}$ Colorimeter (Konica Minolta, Tokyo, Japan). The readings were obtained at the basal portion of the pericarp and expressed as $L^{*}, a^{*}, b^{*}$ modulus in accordance with the CIE color system (1976) for color measurement, specification, and adjustment. In this system, a color solid is defined by three rectangular coordinates from which units or points of approximate visual uniformity are obtained (McGuire, 1992). Coordinate $L^{*}$ indicates lightness, and it varies from zero (completely black) to 100 (completely white). Coordinate $a^{*}$ expresses the degree of green-red variation (increasingly negative values indicate stronger green and increasingly positive values indicate stronger red) and coordinate $b^{*}$ expresses blue-yellow variation (increasingly negative values indicate stronger blue and increasingly positive values indicate stronger yellow).

In addition to these variables, the chroma value $\left(C^{*}\right)$, which expresses the color intensity or saturation, and the hue color angle $\left(h^{\circ}\right)$, which indicates the observable color, were also determined. The hue color angle can vary between $0^{\circ}$ and $360^{\circ}$, where $0^{\circ}$ corresponds to red, $90^{\circ}$ corresponds to yellow, $180^{\circ}$ corresponds to green, and $270^{\circ}$ corresponds to blue. Lastly, the pericarp color index (CI) was calculated using the following formula $\mathrm{CI}=\left(180-h^{\circ}\right) /\left(L^{*}+C^{*}\right)$, which was originally defined for red grapes (Carreño et al., 1995).

As for the chemical characteristics, soluble solid content (SS) was determined using a DR301-95 ${ }^{\circledR}$ digital bench-top refractometer with automatic temperature compensation (Krüss Optronic, Hamburg, Germany). A mixer has been used for 5 min to grind the pulp of individual fruits into a mush; the results were recorded in degrees Brix $\left({ }^{\circ} \mathrm{Bx}\right)$. Titratable acidity (TA) and $\mathrm{pH}$ were measured by titration of $10 \mathrm{~mL}$ mush plus distilled water to a final volume of $50 \mathrm{~mL}$ with a standard solution of $0.1 \mathrm{~N} \mathrm{NaOH}$ in a TritoLine ${ }^{\circledR}$ Easy digital potentiometric titrator (Schott-Geräte $\mathrm{GmbH}$, Mainz, Germany). The final titration point adopted in these measurements was $\mathrm{pH}=8.2$ and the results are reported as citric acid\% (Pregnolotto and Pregnolotto, 1985). Finally, the ratio of SS values to TA values (SS/TA ratio) was obtained.

The physical and chemical characteristics of the fruits were compared through analysis of variance (ANOVA) and polynomial regression analyses to determine the effects of DAA (P $<0.05)$; in addition, Pearson's correlations $(\mathrm{P}<0.05)$ were determined.

\section{RESULTS AND DISCUSSION}

Over the 12-day harvest period, LL did not vary significantly in the pitaya fruit, with a range of 10.6 to $11.7 \mathrm{~cm}$. In contrast, Centurion Yah et al. (2008) found an increase in LL during maturation with a maximum of $8.9 \mathrm{~cm}$ at 31 DAA for $H$. undatus fruit grown between

May and July at a mean temperature of $26.1^{\circ} \mathrm{C}$ and rainfall of $73.9 \mathrm{~mm}$. In a study of reproductive phenology and fruit quality during the summer and autumn at Sinaloa, Mexico $\left(29^{\circ}-26^{\circ} \mathrm{C}\right)$, Osuna Enciso et al. (2007) reported a mean LL of $14.3 \mathrm{~cm}$ for the same species.

$\mathrm{ED}$ of the pitaya fruits increased linearly over the 12-day period, growing from 7.0 to $7.9 \mathrm{~cm}$ (Figure 2). In their study of pitaya fruit maturation, Centurion Yah et al. (2008) observed continuous growth to an ED of $8.2 \mathrm{~cm}$ at $31 \mathrm{DAA}$; this value is close to that obtained here (7.9 cm); which was also found by Osuna Enciso et al. (2007). Martínez Chávez (2011) described pitaya fruits with ED varying between 5.2 and $7.8 \mathrm{~cm}$ in Hylocereus spp. 


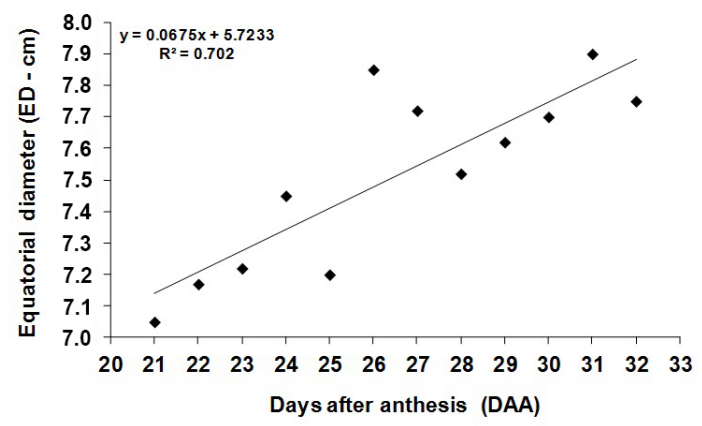

Figure 2. Equatorial diameter (ED) of pitaya fruits from 21 to 32 days after anthesis (DAA).

PeT varied from 1.06 to $0.17 \mathrm{~cm}$ over the harvest period, and the data fitted a $2 \mathrm{nd}$ degree polynomial regression model. During pitaya fruit maturation, PuT increased linearly from 4.60 to $7.17 \mathrm{~cm}$ over the 12-day period (Figure 3). Martínez Chávez (2011) evaluated six pitaya genotypes in Hylocereus spp and found a range of PeT of 0.22 to $0.42 \mathrm{~cm}$, whereas Márquez-Guzmán et al. (2005) reported PeT of 0.26 to $0.37 \mathrm{~cm}$ for five $H$. undatus genotypes.
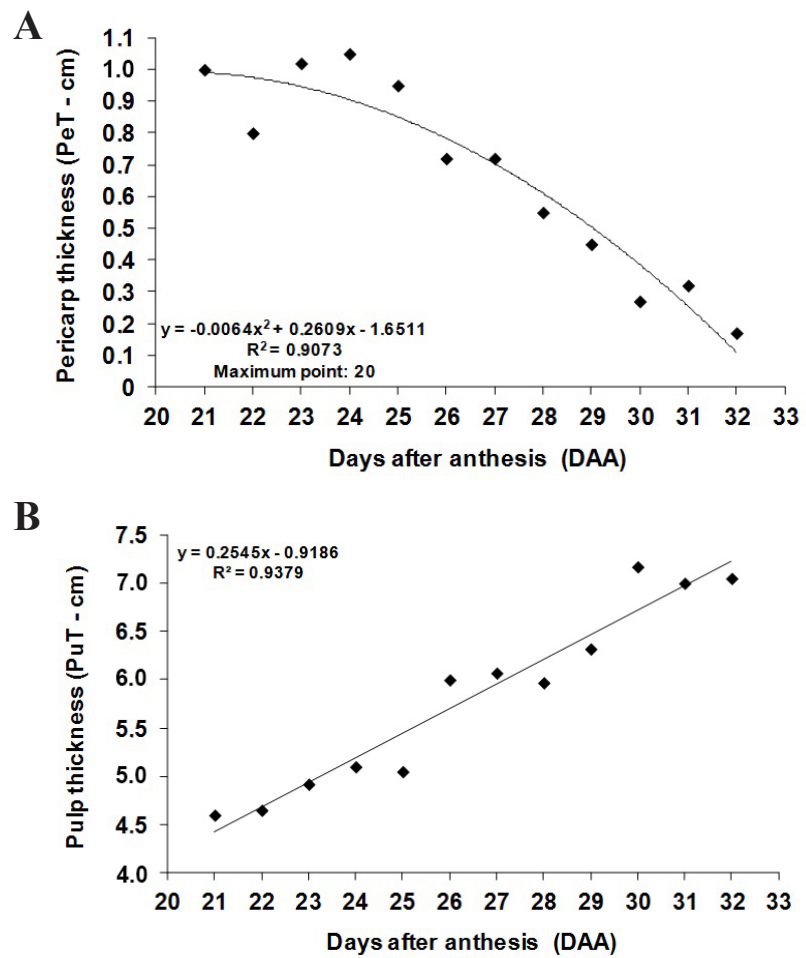

Figure 3. A. Pericarp thickness (PeT) and B. pulp thickness (PuT) of pitaya fruits from 21 to 32 days after anthesis (DAA). 
Our data for FM, PuM, and PeM over the 12-day period are shown in Figure 4. Note that both FM and PuM fitted a linear function. Similar results were reported for H. undatus by Centurion Yah et al. (2008); they found that FM increased linearly to $469.2 \mathrm{~g}$ at 31 DAA. By comparison, we found an increase from 293.1 to $416.2 \mathrm{~g}$ at 32 DAA (Figure 4A). Osuna Enciso et al. (2007) reported a mean FM of $442.0 \mathrm{~g}$, while Nerd et al. (1999) reported a mean FM of $437.5 \mathrm{~g}$.

We found that PuM increased linearly over the 12-day harvest period to a maximum of $253.3 \mathrm{~g}$ at $32 \mathrm{DAA}$ (Figure 4B). These data are consistent with those of Centurion Yah et al. (2008) who reported an increase as the fruit matured and a maximum mean PuM of $368.9 \mathrm{~g}$ at 31 DAA. PuM of $188.4 \mathrm{~g}$ (Castillo-Martínez et al., 2003), $297.8 \mathrm{~g}$ (Osuna Enciso et al., 2007) and 139.6 to $320.1 \mathrm{~g}$ in five H. undatus genotypes (Márquez-Guzmán et al., 2005) have also been reported.
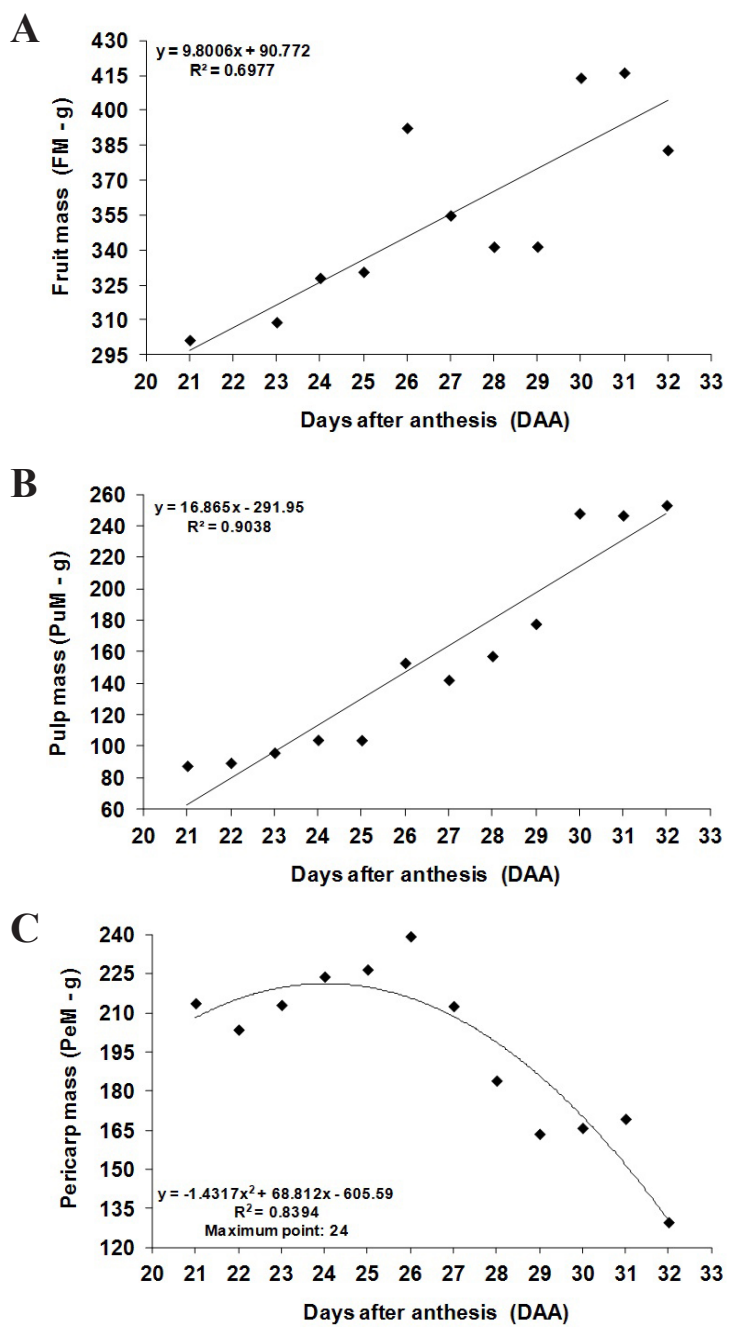

Figure 4. A. Fruit mass (FM), B. pulp mass (PuM) and C. pericarp mass (PeM) of pitaya fruits from 21 to 32 days after anthesis (DAA). 
In contrast to FM and PuM, we found that the data for PeM fitted a quadratic function and had a maximum at 24 DAA (Figure 4C). Centurion Yah et al. (2008) obtained similar results in their evaluation of fruit development in $H$. undatus; for PeM, they reported an increase until the 20th DAA and a subsequent decline until 31 DAA. The smallest PeM value $(129.7 \mathrm{~g})$ here was obtained was at 32 DAA (Figure 4C). Therefore, we conclude that as pitaya fruits mature, PeM decreases while PuM increases. Márquez-Guzmán et al. (2005) and Martínez Chávez (2011), in their studies of different $H$. undatus genotypes, observed PuM ranging from 72.4 to $120.5 \mathrm{~g}$ and 57.9 to $140.6 \mathrm{~g}$, respectively. Thus, variability also exists within the species.

We calculated the relative sizes of the pericarp and pulp masses compared to the fruit mass as the $\% \mathrm{Pe}$ and $\% \mathrm{Pu}$. Over the 12-day harvest period, \%Pe fell from 71.3 to $34.0 \%$ (Figure 5A), whereas $\% \mathrm{Pu}$ rose from 28.7 to $66.0 \%$. Given that the pulp is the edible part of the fruit, these results are favorable.

At 32 DAA, the fruits contained $66.0 \%$ pulp (Figure 5A); Márquez-Guzmán et al. (2005) reported $73.0 \%$ pulp in H. undatus fruits and Osuna Enciso et al. (2007) recorded 79.0\% pulp at 31 DAA; the period considered the start of physiological maturity (Centurion Yah et al., 2008). In the six pitaya genotypes examined by Martínez Chávez (2011), the pulp ranged from 40.5 to $80.6 \%$, a range that includes the result obtained here, despite the occurrence of intra-specific variation.
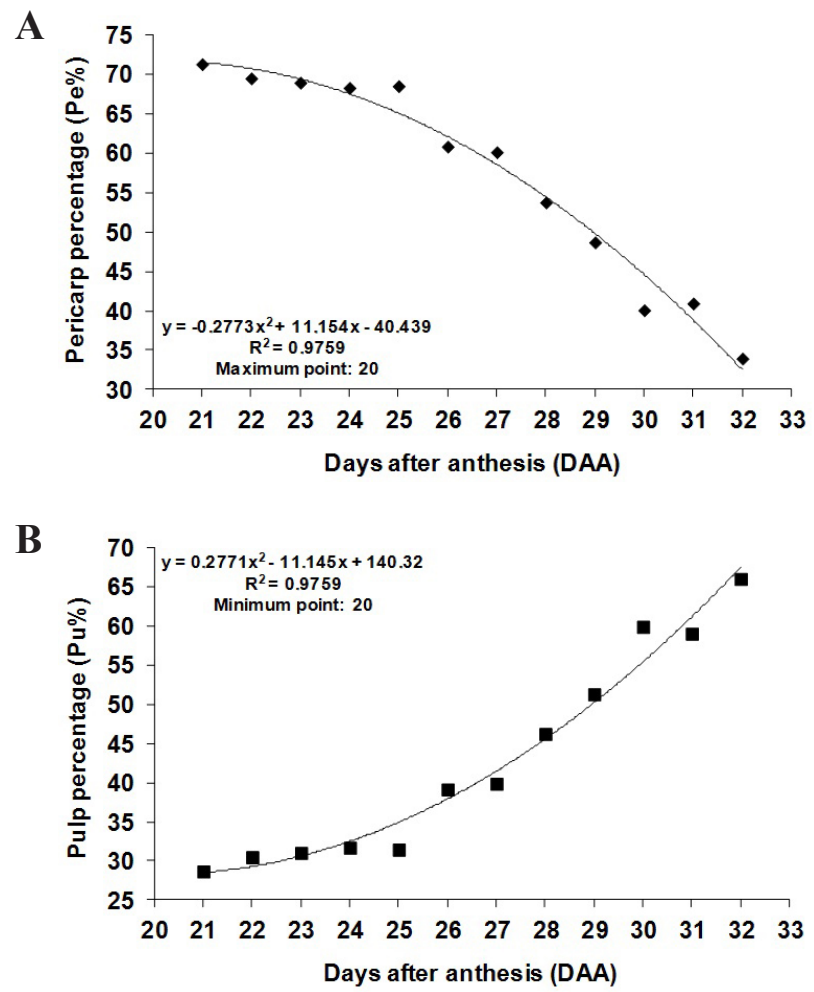

Figure 5. A. Pericarp percentage $(\% \mathrm{Pe})$ and $\mathbf{B}$. pulp percentage $(\% \mathrm{Pu})$ during the maturation of pitaya fruits from 21 to 32 days after anthesis (DAA). 
Centurion Yah et al. (2008) assessed physical changes in $H$. undatus fruits and concluded that fruits at 25 DAA contained $39.9 \%$ pericarp, a value that decreased to $20.4 \%$ at 31 DAA. These values are below those reported by Nerd et al. (1999), who found 57.5 and $32.5 \%$ pericarp, respectively. In the present study, we obtained a higher $\% \mathrm{Pe}$, but a similar trend was present as the estimate fell from 69.0 to $41.0 \%$ as the fruit matured (Figure 5B). One drawback to this change is that it makes the pericarp thinner and more sensitive to post-harvest tearing and damage (Centurion Yah et al., 2008).

We found here that the pulp to pericarp ratio $(\mathrm{Pu} / \mathrm{Pe})$ increased during the sampling period ( 0.40 to 1.98$)$ as the result of the increased pulp mass and decreased pericarp mass (Figure 4). Our polynomial regression analysis indicated the ratio peaked at 32 DAA (Figure 6).

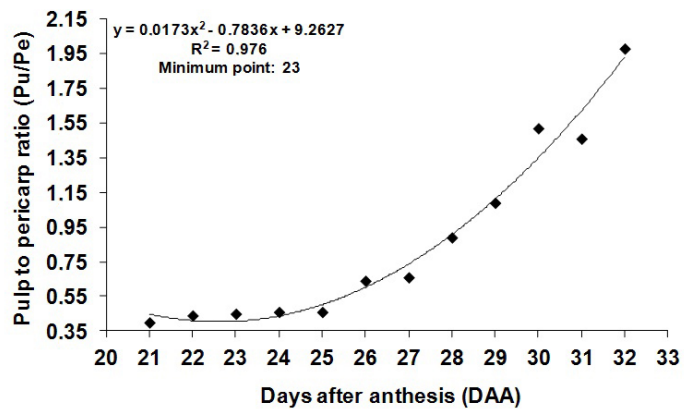

Figure 6. Pulp to pericarp ratio $(\mathrm{Pu} / \mathrm{Pe})$ of pitaya fruits from 21 to 32 days after anthesis (DAA).

Centurion Yah et al. (2008) reported that pitaya fruit color begins to change at 25 DAA. At this time, PuM and PeM were 188.7 and $125.1 \mathrm{~g}$, respectively, producing a $\mathrm{Pu} / \mathrm{Pe}$ ratio of 1.5. At $31 \mathrm{DAA}, \mathrm{PuM}$ and PeM were 368.9 and $94.8 \mathrm{~g}$, respectively, giving a ratio of 3.9. Thus, during the period of fruit color change, the edible portion of the fruit (pulp) increases while the pericarp decreases.

A regression analysis showed that the pericarp CI increased with time in the present study, shifting from green to incipient red at 28 DAA and turning completely red after 30 DAA (Figure 7). Centurion Yah et al. (2008) observed that at 25 DAA, pitaya fruits had a light green pericarp with some incipient red; at 27 DAA, the pericarp turned yellowish-green with red zones over 10 to $20 \%$ of the surface; at 29 DAA, the fruits were bright red over $70 \%$ of the surface; and at $31 \mathrm{DAA}$, the fruits were completely red-purple.

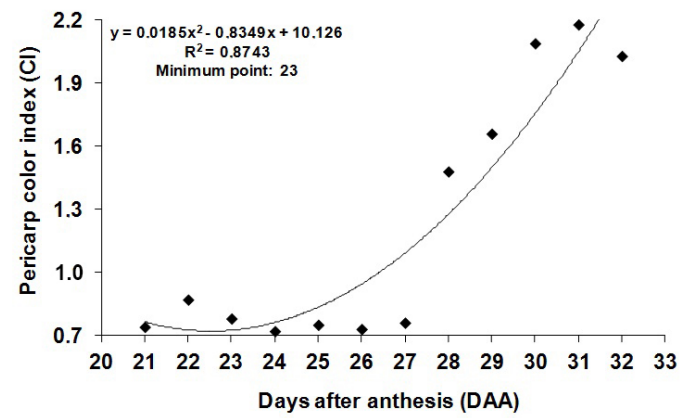

Figure 7. Pericarp color index (CI) of pitaya fruits from 21 to 32 days after anthesis (DAA). 
According to Castillo-Martínez and Ortíz-Hernández (1994) and Centurion Yah et al. (2008), the first change in H. undatus pericarp color occurs at 24 to 25 DAA; however, in the present study, this change occurred at 28 to 29 DAA (Figure 7). According to Nerd et al. (1999) and Centurion Yah et al. (2008), the pericarp of pitaya fruits becomes completely red 4 to 5 days after the first change in color; we obtained similar results in showing this change occurred between the 30th and 32nd DAA. A study in Vietnam, where H. undatus fruits are harvested when they turn red, found that the change occurs between the 28th and 30th DAA (To et al., 2002).

Color is an important parameter for producers and consumers because it indicates whether the fruit displays the ideal conditions for commercialization and consumption. However, in most cases, color does not contribute to an effective increase in the nutritional value or quality of the product (Chitarra and Chitarra, 2005). Nevertheless, consumers, in general, prefer strongly colored and shiny fruits (Hirsch et al., 2012). The degreening of the pericarp to produce the typical fruit color for the species provides an important indicator of the state of maturation of the fruit (Chitarra and Chitarra, 2005) and of the optimal time for harvest (Tucker, 1993).

The data for hue color angles $\left(h^{\circ}\right)$ fitted a quadratic curve (Figure 8). When harvesting began, the fruit pericarp was green-yellow $\left(118^{\circ}\right)$; as maturation advanced the hue changed to $80-64^{\circ}$ at 28 to $29 \mathrm{DAA}$ (as red coloration began to develop); the fruits become completely red at the 30 th DAA $\left(23^{\circ}\right)$ and increased in intensity at 31-32 DAA $\left(10^{\circ}\right)$. Similarly, Centurion Yah et al. (2008) reported a decrease in mean color angle values during maturation from $116.6^{\circ}(25$ $\mathrm{DAA}), 108.3^{\circ}(27 \mathrm{DAA}), 91.4^{\circ}$ (29 DAA), to $51.0^{\circ}$ (31 DAA).

According to Wybraniec and Mizrahi (2002) and Le Bellec et al. (2006), the red coloration of the pericarp in Hylocereus spp fruit is the result of accumulation of betacyanins. Synthesis of these pigments is activated by the high availability of sugar and light, among other factors (Castellar et al., 2003). As the fruit maturation process advances, there is an increase in the amount of soluble sugars leading to increase in betacyanin production and a reduction in the color angle values in the fruit. Phebe et al. (2009) showed that there was a significant negative correlation between hue color angles and total betacyanin contents in pericarps of $H$. polyrhizus with a drastic increase of $90 \%$ between 25 and 30 DAA.

Centurion Yah et al. (2008) reported a color angle value of $51^{\circ}$ for $H$. undatus at 31 DAA, which is higher than the average $10^{\circ}$ angle obtained here. This value is within the range recommended by To et al. (2002) who suggested values equal to or below $30^{\circ}$ for commercial harvesting of pitaya; this value was obtained here from the 30th DAA (Figure 8). Osuna Enciso et al. (2011) evaluated the pitaya maturity at three harvest times and obtained fully mature fruits with values below $30^{\circ}$; this value is near the angle range corresponding to red $\left(0^{\circ}\right)$.

The lightness index $\left(L^{*}\right)$ is important to consumers as lightness contrast allows the fruits to be more attractively displayed. Martínez Chávez (2011) evaluated the shininess of the fruit from six pitaya genotypes and showed the occurrence of variation with a range from 60.3 (shiniest) to 29.7 (least shiny). In the present study, the lightness index fell from 50.7 to 37.8 as the fruits matured, indicated that the color of the fruit had become darker (Figure 8). However, Centurion Yah et al. (2008) did not find any significant differences in lightness during the development of fruit from this species.

The changes in chroma $\left(C^{*}\right)$ values, from 28.5 to 45.1 , indicated that color intensity increased during maturation. This increase in intensity of pericarp color may encourage fruit acceptance by consumers. Regarding the variable $b^{*}$ which expresses the degree of blue (toward negative) to yellow (toward positive) variation, we identified a decreasing trend with time: the mean value was 30.6 at $21 \mathrm{DAA}, 21.1$ at $29 \mathrm{DAA}, 12.3$ at $30 \mathrm{DAA}, 6.2$ at $31 \mathrm{DAA}$, and 7.6 at 32 DAA (Figure 8). 

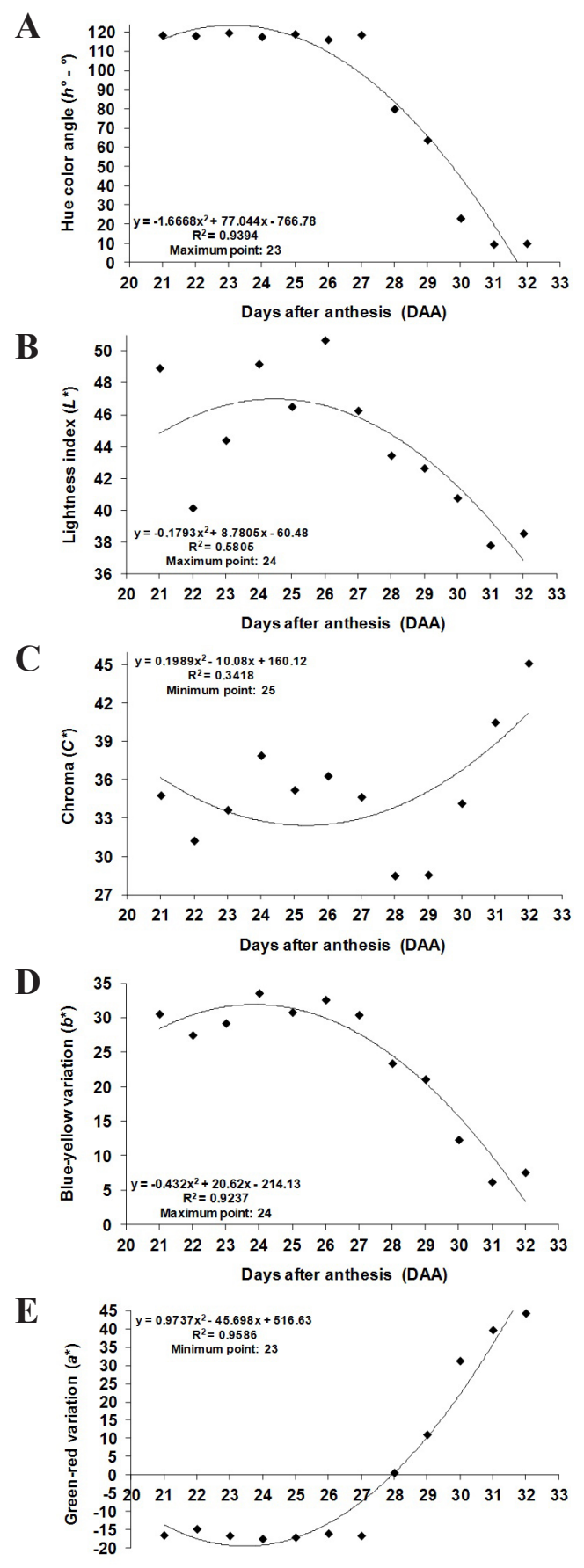

Days after anthesis (DAA)

Figure 8. A. Hue color angle $\left(h^{\circ}\right)$, B. lightness index $\left(L^{*}\right)$, C. chroma $\left(C^{*}\right)$, D. blue-yellow variation $\left(b^{*}\right)$, and $\mathbf{E}$. green-red variation $\left(a^{*}\right)$ of the pericarp of pitaya fruits from 21 to 32 days after anthesis (DAA). 
The final variable we scored to assess color changes in the pericarp was $a^{*}$, which represents the degree of green (toward negative) to red (toward positive) variation. We found that $a^{*}$ increased with time from -16.4 at $21 \mathrm{DAA}$, to 11.1 at $29 \mathrm{DAA}, 31.3$ at $30 \mathrm{DAA}, 39.7$ at 31 DAA, and 44.4 at 32 DAA (Figure 8).

We analyzed various chemical characteristics in pitaya fruit pulp from fruits harvested over the interval 21st to 32nd DAA. The data on solid soluble (SS) contents fitted a 2nd degree curve with a maximum value of $12.2^{\circ} \mathrm{Bx}$ at the 31 st DAA (Figure 9). Centurion Yah et al. (2008) suggested there was a close relationship between color development and SS contents in H. undatus. They found that fruits at 20 days of development had an SS content of $4.6^{\circ} \mathrm{Bx}$, a value below that when fruit harvesting began at $21 \mathrm{DAA}\left(7.6^{\circ} \mathrm{Bx}\right)$ and at $31 \mathrm{DAA}\left(12.6^{\circ} \mathrm{Bx}\right)$; these results are consistent with our findings.

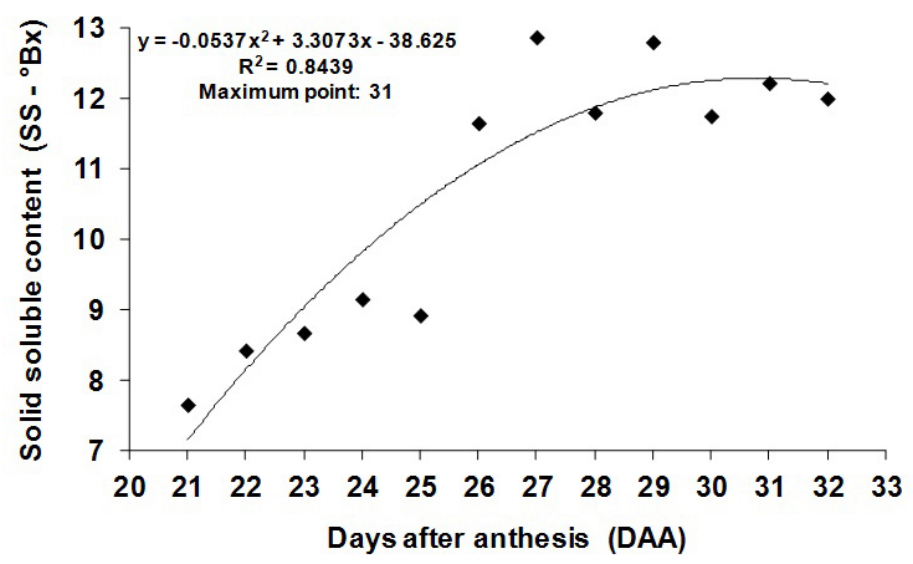

Figure 9. Solid soluble content (SS) in pitaya fruits from 21 to 32 days after anthesis (DAA).

Osuna Enciso et al. (2011) measured SS contents at different harvest times; the fruit was harvested at the initial maturation stage ( 25 to $50 \%$ of the pericarp surface red), intermediate maturation (50 to $75 \%$ ) and full maturation ( 75 to $100 \%$ ), and they found similar values to those of this study for fruits harvested at intermediate and full maturity (12.4 and 13.6 ${ }^{\circ} \mathrm{Bx}$ ). Additionally, the same authors had observed after 12 days of storage that these SS values dropped by one or two units. Other authors reported similar results for fruit with red pericarp and white pulp. For example, Castillo-Martínez et al. (2003) found an SS content of $11.9^{\circ} \mathrm{Bx}$, while Márquez-Guzmán et al. (2005) reported values ranging from 10.9 to $14 .{ }^{\circ} \mathrm{Bx}$ in four pitaya genotypes. However, fruit with higher SS contents have also been recorded. Martínez Chávez (2011) studied six pitaya genotypes and found SS contents ranging from 14.5 to 17.6 ${ }^{\circ} \mathrm{Bx}$; Livera-Muñoz et al. (2010) found that fruit varieties with a red-purple pericarp and white pulp had values from 12.0 to $16.0^{\circ} \mathrm{Bx}$.

Centurion Yah et al. (2008) found that pitaya fruit flavor varies between bittersweet and sweet from 27 to $31 \mathrm{DAA}$, and that acceptance of the fruit by consumers was optimal between 29 and 31 DAA. Merten (2003) reported that in California, pitaya fruit physiological maturity occurs between 40 and 45 DAA when the fruit reaches maximum SS content.

Nerd et al. (1999) reported values between 16 and $17^{\circ} \mathrm{Bx}$ during an evaluation of two 
species of Hylocereus and determined that sugar accumulation during pitaya fruit maturation is related to a decrease in starch content and pulp mucilage and that there is no contribution from pericarp metabolism. This contrasts with the situation in Opuntia ficus-indica (L.) Miller fruit (de La Barrera and Nobel, 2004).

TA was found here to fit a quadratic function in a regression analysis; in contrast to SS contents, maximum TA occurred at an earlier time, namely 26 DAA. At 21 DAA, the fruits displayed lower acidity $(0.40 \%)$; acidity then increased until a maximum value of $>1.0 \%$ was reached. TA subsequently decreased to a value of $0.27 \%$ at $32 \mathrm{DAA}$ (Figure 10). This behavior is consistent with that described by Wills et al. (1998), who ascertained that the decrease in organic acids during fruit maturation was the result of them being used as substrates for respiration.

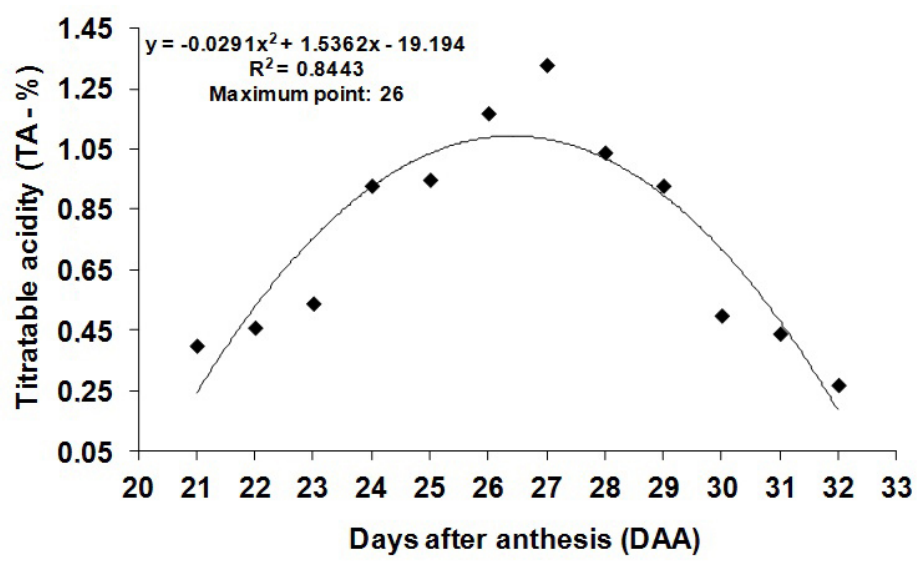

Figure 10. Titratable acidity (TA) in pitaya fruits from 21 to 32 days after anthesis (DAA).

Nerd et al. (1999) found a similar trend in H. undatus and H. polyrhizus fruits, namely that acidity was higher in fruits during color change than in those in which color change was advanced. According to Centurion Yah et al. (1999), consumers find the taste of fruits with a TA of $0.24 \%$ acceptable; this conclusion is consistent with the $0.27 \%$ at 32 DAA, the final day of harvest (Figure 10). Acceptance was found to increase because of flavor of the fruit that is produced from 29 to 31 DAA (Centurion Yah et al., 2008).

Several authors have assessed the acidity of Hylocereus spp fruits and reported values close to those found in this study, such as $0.24 \%$ (Centurion Yah et al., 1999), 0.30\% (Sornyatha and Anprung, 2009), 0.36\% (Arévalo-Galarza and Ortíz-Hernández, 2004), 0.40\% (Centurion Yah et al., 2008), and 0.30 to $0.60 \%$ in six different genotypes (Martínez Chávez, 2011). However, in their comparison of fruits harvested at different stages of maturation, Osuna Enciso et al. (2011) found that acidity values fell from 0.92 in the least mature, to 0.76 at an intermediate stage, and to $0.63 \%$, in ripe fruit, indicating that mature fruits are less acidic. According to Arévalo-Galarza and Ortíz-Hernández (2004), the increase in acidity before the change in fruit color indicates the beginning of the maturation processes; moreover, the reduction in acidity of the pitaya pulp can be a problem, as it does not permit determination of the sweetness of the fruit. 
We also analyzed the SS/TA ratio and found that the minimum value was reached at 25 DAA because of increased acidity (Figure 11). To et al. (2002) proposed that the best indicator for pitaya flavor was the SS/TA ratio and that the ideal value is approximately 40 , which occurs in mature fruits with $0.40 \%$ acidity. Here, we found a ratio higher than this optimum at 32 DAA (55.5) (Figure 11); this high ratio resulted from progressive decrease in acidity after 26 DAA (Figure 10).

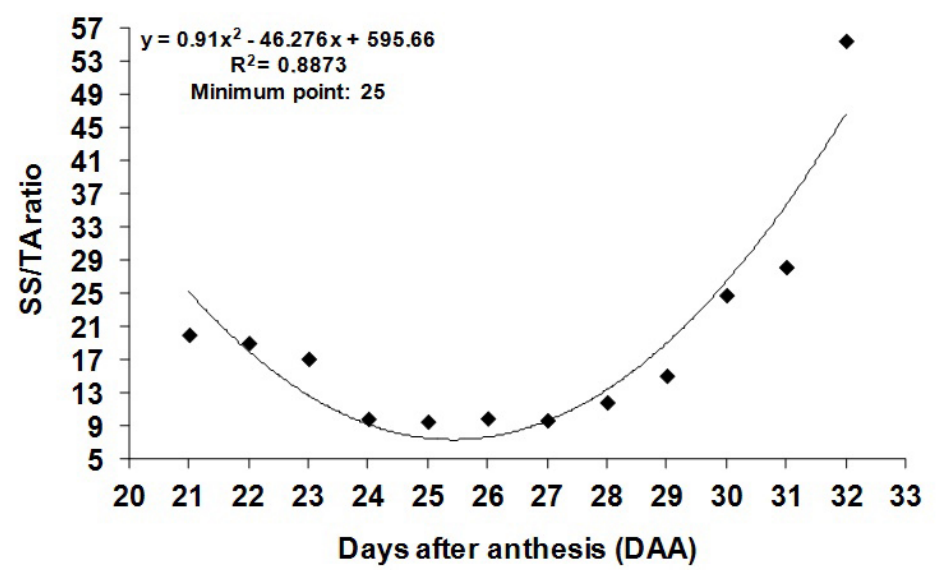

Figure 11. SS/AT ratio in pitaya fruits from 21 to 32 days after anthesis (DAA).

Martínez Chávez (2011) found that the increase in the SS/TA ratio was a result of a drop in acidity from 1.40 to $0.40 \%$; they also obtained ratios between 33.1 and 48.6 in the six genotypes studied. Centurion Yah et al. (2008) reported an increase from 20.6 to 35.5 between the 25 th and 31 st DAA, which was associated with a significant reduction in acidity from 1.20 to $0.40 \%$.

According to Thé et al. (2001), fruit flavor is in large part a result of the balance between acids and sugars; this balance can be assessed by the SS/TA ratio. The SS/TA ratio increases during maturation because of reduced TA and increased SS content, and indicates the appropriate time for harvesting and storing the fruit or for its immediate consumption. By contrast, Osuna Enciso et al. (2011) suggested that as the changed ratio was caused by the drastic reduction of TA, then a high SS/TA ratio could not be an indicator of quality because there was no increase in SS content. Here, however, in addition to the reduction in acidity after 26 DAA, which continued to 32 DAA (Figure 10), we found an increase in SS content (Figure 9) that contributed to the increased SS/TA ratio (Figure 11). This characteristic was reported by Centurion Yah et al. (1999) and Nerd et al. (1999) and was suggested to be indicative of an "insipid" flavor in pitaya fruits.

During maturation, the $\mathrm{pH}$ of the $H$. undatus fruit changed in an inverse manner to acidity; thus $\mathrm{pH}$ values were initially high but declined until the 28th DAA when they began to increase again (Figure 12). This behavior was consistent with the result from the TA analysis (Figure 10) because a higher $\mathrm{pH}$ corresponds to a lower acidity and viceversa. 


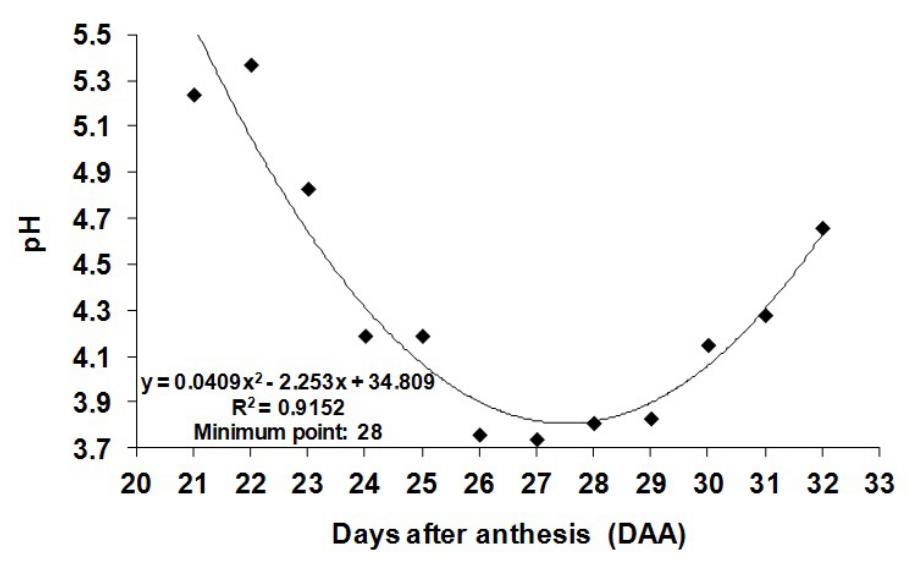

Figure 12. $\mathrm{pH}$ in pitaya fruits from 21 to 32 days after anthesis (DAA).

At $32 \mathrm{DAA}$, the average $\mathrm{pH}$ was 4.6 (Figure 12). Similar values were reported by Esquivel et al. (2007) in their study of Hylocereus spp; they found $\mathrm{pH}$ values ranging from 4.2 to 4.9. Similarly, Stintzing and Carle (2006) reported $\mathrm{pH}$ between 4.3 and 4.7. However, Cálix de Dios and Castillo-Martínez (2008) found a pH of 1.7 in the H. undatus subspecies luteocarpus. Rodríguez Rodríguez et al. (2005), working with yellow pitaya (Selenicereus megalanthus), observed that the mature harvested fruit had a high $\mathrm{pH}$, a result consistent with those obtained in this study (Figure 12).

We analyzed all the variables described above and considered significant correlations with strong linear dependency above 0.80 (Table 1) (Ortiz et al., 2014). PuM had a strong positive linear association with $\mathrm{PuT}, \mathrm{FM}, \% \mathrm{Pu}, \mathrm{Pu} / \mathrm{Pe}, \mathrm{CI}, a^{*}$, and $\mathrm{SS}$ content, and a strong inverse linear association with $\mathrm{PeM}, \% \mathrm{Pe}, h^{\circ}$, and $b^{*}$. Therefore, $\mathrm{PuM}$ was the most appropriate variable for determining the maturation of pitaya fruits, as it showed strong correlations with 12 other characteristics analyzed.

The variables $\% \mathrm{Pe}, \% \mathrm{Pu}, h^{\circ}$, and $a^{*}$ were also found to be efficient for identifying the physiological maturity of $H$. undatus fruits because they had strong linear correlations with 10 other variables, while $\mathrm{PeM}, b^{*}, \mathrm{CI}$, and $\mathrm{Pu} / \mathrm{Pe}$, showed correlations to 9, 9, 8, and 7 other variables, respectively. The PuT value was strongly and inversely proportional with \% $\mathrm{Pe}$ and $h^{\circ}$ and directly proportional to $\mathrm{FM}, \mathrm{PuM}, \% \mathrm{Pu}, a^{*}$, and $\mathrm{SS}$ content.

The variables FM and SS content had strong and positive linear correlations with ED, $\mathrm{PuT}, \mathrm{PuM}$, and \% $\mathrm{Pu}$, and negative correlations with \%Pe. According to Nerd et al. (1999), the development of $H$. undatus fruit color is related to SS content, which is consistent with the data shown in Table 1. Here, we identified a weak significant correlation $(\rho<0.80)$ in which the SS content was in direct proportion to the CI and $a^{*}$ values and in inverse proportion to $h^{\circ}$ and $b^{*}$ values.

Among the characteristics under assessment, $L^{*}$ and ED showed least association to the others. $L^{*}$ showed a direct proportional correlation with PeM, $h^{\circ}$, and $b^{*}$ and an inverse proportional correlation to $a^{*}$; ED was directly correlated with FM and SS content. The only variables that did not strongly correlate to any other were PeT and $C^{*}$. The remaining variables did not show significant or strong correlations. 


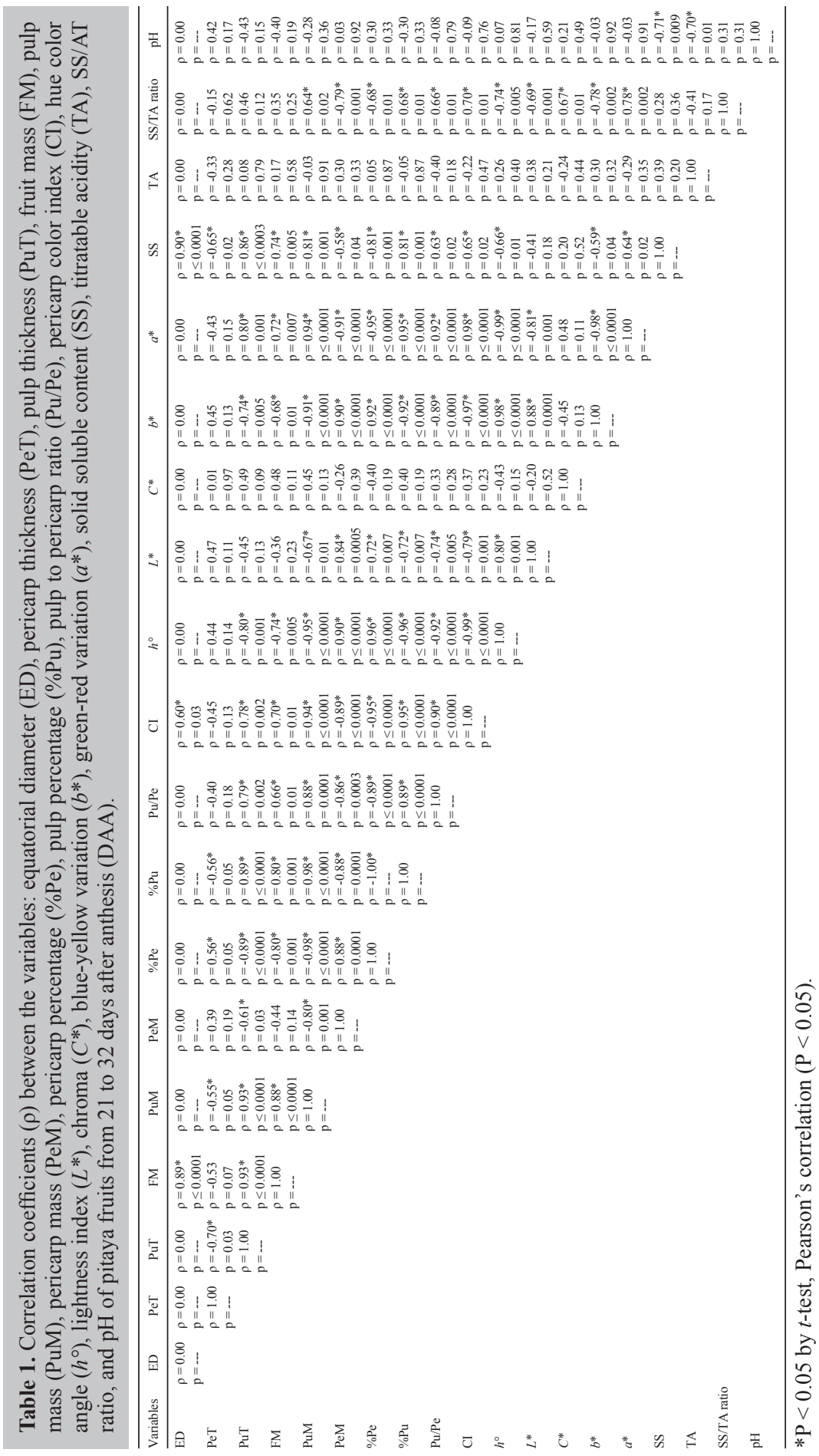


According to Cavalini (2004), the use of more than one variable to characterize the stage of maturation allows greater precision in classifying fruit stages. Furthermore, knowing the correlations among the characteristics for maturation, one variable can be validated based on another. Nevertheless, the correlation test should not be used in isolation to identify the point of physiological maturity of the fruit as this may lead to incomplete or incorrect information. A significant correlation indicates that there is a similar variation trend between two variables, but does not mean there is a corresponding precision in attaining a given point.

Castillo-Martínez and Ortíz-Hernández (1994) found that the period of pitaya fruit maturation runs from the first manifestation of red color in the pericarp until the appearance of brown-colored streaks. As this latter state implies a loss in the commercial value of the fruit, they suggested that the stage of useful harvest was between 25 and 31 DAA. Similar estimates for the maturation period were obtained in other studies, such as 28 to 30 DAA (To et al., 2002), 29 to 31 DAA (Centurion Yah et al., 2008), and 25 to 31 DAA (Martínez Chávez, 2011).

The results of these studies are consistent with those obtained in the present study, where it was observed that physical and chemical characteristics had an influence on the maturation of pitaya fruits as a result of the significant differences that occurred during harvest (except for changes in LL). H. undatus fruit grown in Londrina-PR, Brazil, reached physiological maturity between 30 and 32 DAA; the fruit turned completely red at 30 DAA, and the tone became more intense at 31-32 DAA, as shown by the increase in the pericarp CI, $a^{*}$, and decrease in $h^{\circ}$, which reached values corresponding to red coloration. At 31 DAA, the SS contents were at their peak, and at $32 \mathrm{DAA}$, there was an increase in the $\mathrm{Pu} / \mathrm{Pe}$ and a decrease in PeM. In addition, TA, $\mathrm{pH}$ and $\mathrm{SS} / \mathrm{TA}$ ratio reached the values recommended in the literature for this species.

\section{CONCLUSIONS}

Our analysis showed that Hylocereus undatus fruit grown in Londrina, PR, Brazil, reached physiological maturity between 30 and 32 DAA. During this optimal period for harvest, the fruit became completely red with high soluble solid contents, and reached the recommended values of titratable acidity, $\mathrm{pH}$, and SS/TA ratio for this species. Fruit equatorial diameter, pulp thickness, fruit mass, pulp mass, pulp percentage, and pulp/pericarp ratio also increased within this period, with a reduction in pericarp thickness, pericarp mass, and pericarp percentage; these latter traits are desired by both producers and consumers. We determined that pulp mass was the variable that showed more strong's association with other variables analyzed in this study.

\section{Conflicts of interest}

The authors declare no conflict of interest.

\section{ACKNOWLEDGMENTS}

The authors would like to thank the National Council for Scientific and Technological Development (Conselho Nacional de Desenvolvimento Científico e Tecnológico - CNPq) and the Brazilian Federal Agency for the Support and Evaluation of Graduate Education (Coordenação de Aperfeiçoamento de Pessoal de Nível Superior - CAPES) for granting the 
first author's scholarship and the Araucária Foundation (Fundação Araucária) for the second author's Productivity Grant. In addition, the authors thank Dr. Alessandro Borini Lone and Dr. Adriane Marinho de Assis for their help in harvest and conducting the experiment.

\section{REFERENCES}

Andrade RA, Martins ABG and Silva MTH (2008). Development of seedlings of red pitaya (Hylocereus undatus Haw) in different substrate volumes. Acta Sci. Agron. 30: 697-700.

Arévalo-Galarza ML and Ortíz-Hernández YD (2004). Comportamiento postcosecha del fruto de la pitahaya (Hylocereus undatus) [Post-harvest behavior of pitahaya fruit (Hylocereus undatus)]. Cact. Suculentas Mex. 49: 85-90.

Bastos DC, Pio R, Scarpare Filho JA, Libardi MN, et al. (2006). Propagação da pitaya 'vermelha' por estaquia [Propagation of 'red' pitaya through cuttings]. Cienc. Agrotec. 30: 1106-1109.

Cálix de Dios HC and Castillo-Martínez R (2008). Estudio sobre la pitahaya amarilla de la Península de Yucatán [Study on the yellow pitaya of the Yucatan Peninsula]. Rev. Trop. Rural 1: 31-35.

Carreño J, Martínez A, Almela L and Fernández-Lópes JA (1995). Proposal of an index for the objective evaluation of the color of red table grapes. Food Res. Int. 24: 373-377.

Castellar R, Obón JM, Alacid M and Fernández-López JA (2003). Color properties and stability of betacyanins from Opuntia fruits. J. Agric. Food Chem. 51: 2772-2776.

Castillo-Martínez R and Ortíz-Hernández YD (1994). Floración y fructificación de pitajaya en Zaachila, Oaxaca [Flowering and fruiting of pitahaya in Zaachila, Oaxaca]. Rev. Fitotecnia Mex. 17: 12-19.

Castillo-Martínez R, Livera-Muñoz M, Brechú Franco AE and Márquez-Guzmán J (2003). Compatibilidad sexual entre dos tipos de Hylocereus (Cactaceae) [Sexual compatibility between two types of Hylocereus (Cactaceae)]. Rev. Biol. Trop. 51: 699-706.

Castro MM, Godoy AR and Cardoso AII (2008). Qualidade de sementes de quiabeiro em função da idade e do repouso pós-colheita dos frutos [Okra seed quality in the function of fruit age and post-harvest rest]. Cienc. Agrotec. 32: 1491-1495.

Cavalini FC (2004). Índices de maturação, ponto de colheita e padrão respiratório de goiabas 'Kumagai' e 'Paluma' [Maturation rates, harvest point and respiratory standard of the 'Kumagai' and 'Paluma' guavas]. Master's thesis, USP, Piracicaba.

Centurion Yah AR, Solís Pereira S, Mercado Silva E, Baéz Sañudo R, et al. (1999). Variación de las principales características de la pitahaya (Hylocereus undatus) durante su maduración postcosecha [Variations of the main characteristics of pitahaya (Hylocereus undatus) during its post-harvest maturation]. Hortic. Mex. 7: 419-425.

Centurion Yah AR, Baéz Sañudo R, Pérez Vergara M, Solís Pereira S, et al. (2000). Crecimiento, desarrollo y comercialización de la pitahaya (Hylocereus undatus) durante la postcosecha [Growth, development and commercialization of pitaya (Hylocereus undatus) during the postharvest]. Rev. Iber. Tec. Post. 2: 161-168.

Centurion Yah AR, Solís Pereira S, Saucedo Veloz C, Baéz Sañudo R, et al. (2008). Cambios físicos, químicos y sensoriales en frutos de pitahaya (Hylocereus undatus) durante su desarrollo [Physical, chemical and sensory changes in pitahaya fruits (Hylocereus undatus) during their development]. Rev. Fitotecnia Mex. 31: 1-5.

Chitarra MLF and Chitarra AB (2005). Pós-colheita de frutos e hortaliças: Fisiologia e manuseio [Post-harvest of fruits and vegetables: Physiology and handling]. 2nd edn. UFLA, Lavras.

Chuine I, Kramer K and Hänninen H (2003). Plant development models. In: Phenology: An integrative environmental science (Schwartz MD, ed.). 2nd edn. Kluwer Academic Publishers, Dordrecht, 217-235.

Corrales García J (2003). Caracterización, poscosecha, aprovechamiento e industrialización de Pitayas y Pitahayas [Characterization, post-harvest, processing and industrialization of pitayas and pitahayas]. In: Pitayas y Pitahayas (Flores Valez CA, ed.). Ciestaam, Chapingo, 137-173.

de La Barrera E and Nobel PS (2004). Carbon and water relations for developing fruits of Opuntia ficus-indica (L.) Miller, including effects of drought and gibberellic acid. J. Exp. Bot. 55: 719-729.

Embrapa (2013). Sistema brasileiro de classificação de solos [Brazilian system of soil classification]. 3rd edn. Embrapa, Brasília.

Esquivel P, Stintzing FC and Carle R (2007). Fruit characteristics during growth and ripening of different Hylocereus genotypes. Eur. J. Hortic. Sci. 72: 231-238.

Hirsch GE, Facco EMP, Rodrigues DB, Vizzotto M, et al. (2012). Caracterização físico-química de variedades de amorapreta da região sul do Brasil [Physical-chemical characterization of blackberry varieties in the Southern region of Brazil]. Cienc. Rural 42: 942-947.

Le Bellec F, Vaillant F and Imbert E (2006). Pitahaya (Hylocereus spp.): a new fruit crop, a market with a future. Fruits 
61: 237-250.

Livera-Muñoz M, Ortíz-Hernández YD, Castillo-Martínez R, Castillo-González F, et al. (2010). Pitahaya (Hylocereus spp.): Problemas, logros y perspectivas [Pitahaya (Hylocereus spp.): Problems, achievements and perspectives]. In: La investigación al servicio del campo mexicano (Cruz-Izquierdo S, Muratalla ALY and Kato ATY, eds.). Postgrado en Recursos Genéticos y Productividad-Genética, Montecillo, 57-59.

Márquez-Guzmán JG, Castillo-Martínez R and Livera-Muñoz M (2005). Caracterización morfológica y compatibilidad sexual de cinco genotipos de pitahaya (Hylocereus undatus) [Morphological characterization and sexual compatibility of five pitahaya (Hylocereus undatus) genotypes]. Agrociencia 39: 183-194.

Martínez Chávez R (2011). Relaciones entre genotipo, productividad y calidad de fruto en pitahaya (Hylocereus spp.) [Relationships between genotype, productivity and quality of pitahaya fruits (Hylocereus spp.)]. Master's thesis, Colegio de Postgraduados, Montecillo.

McGuire RG (1992). Reporting of objective color measurements. HortScience 27: 1254-1255.

Merten S (2003). A review of Hylocereus production in the United States. J. Prof. Assoc. Cactus Dev. 5: 98-105.

Nerd A, Gutman F and Mizrahi Y (1999). Ripening and postharvest behavior of fruits of two Hylocereus species (Cactaceae). Postharvest Biol. Technol. 17: 39-45.

Nerd A, Sitrit Y, Kaushik RA and Mizrahi Y (2002). High summer temperatures inhibit flowering in vine pitaya crops (Hylocereus spp.). Sci. Hortic. 96: 343-350.

Ortiz TA, Lone AB, Unemoto LK, Athanázio JC, et al. (2014). Metodologias para avaliação da qualidade fisiológica de lotes de sementes de cenoura cultivar londrina armazenados por até dez anos [Methodologies for evaluation of physiological quality seed lots of carrot cultivar londrina storage for up to ten years]. Biosci. J. 30: 330-337.

Osuna Enciso T, Bustamante Francisco B, Mendoza Torres AL and Zea MF (2007). Fenología reproductiva y calidad del fruto de pitahaya (Hylocereus undatus) en Sinaloa, México [Reproductive phenology and quality of pitahaya fruits (Hylocereus undatus) in Sinaloa, Mexico]. In: Anais do $12^{\circ}$ Congreso Nacional de la Sociedad Mexicana de Ciencias Hortícolas, Zacatecas.

Osuna Enciso T, Ibarra Zazueta ME, Muy Rangel MD, Valdez Torres JB, et al. (2011). Calidad postcosecha de frutos de pitahaya (Hylocereus undatus Haw.) cosechados en tres estados de madurez [Postharvest quality of pitahaya (Hylocereus undatus Haw.) fruits harvested in three maturity stages]. Rev. Fitotecnia Mex. 34: 63-72.

Phebe D, Chew MK, Suraini AA, Lai OM, et al. (2009). Red-fleshed pitaya (Hylocereus polyrhizus) fruit color and betacyanin content depend on maturity. Int. Food Res. J. 16: 233-242.

Pregnolotto W and Pregnolotto NP (1985). Normas analíticas do Instituto Adolfo Lutz: Métodos químicos e físicos para análise dos alimentos [Analytical standards of the Adolfo Lutz Institute: Chemical and physical methods for foodstuff analysis]. 3rd edn. Adolfo Lutz Institute, São Paulo.

Rodríguez Rodríguez DA, Patiño Gutiérrez MP, Miranda Lasprilla D, Fischer G, et al. (2005). Efecto de dos índices de madurez y dos temperaturas de almacenamiento sobre el comportamiento en poscosecha de la pitahaya amarilla (Selenicereus megalanthus Haw.) [Effect of two ripening stages and two storage temperatures on the postharvest behavior of yellow pitahaya (Selenicereus megalanthus Haw.)]. Rev. Facultad Nacional Agronomía 58: 2837-2857.

Silva MTH, Martins ABG and Aparecida de Andrade R (2006). Enraizamento de estacas de pitaya vermelha em diferentes substratos [Rooting of red pitaya cuttings in different substrates]. Rev. Caatinga 19: 61-64.

Sornyatha K and Anprung P (2009). Bioactive compounds and stability of betacyanins from skin and flesh of red dragon fruit (Hylocereus polyrhizus (Weber) Britton \& Rose). J. Agric. Sci. 40: 15-18.

Stintzing FC and Carle R (2006). Cactus fruits - more than color. Fruit Process. 16: 166-171.

Thé PMP, Carvalho VD, Abreu CMP, Nunes RP, et al. (2001). Efeito da temperatura de armazenamento e do estádio de maturação sobre a composição química do abacaxi cv. Smooth cayenne L [Effect of storage temperature and maturation stage on the chemical composition of pineapple from cv. Smooth cayenne L]. Cienc. Agrotec. 25: 356-363.

To LV, Ngu N, Duc ND and Huong HTT (2002). Dragon fruit quality and storage life: effect of harvest time, use of plant growth regulators and modified atmosphere packaging. Acta Hortic. 575: 611-621.

Tucker GA (1993). Introduction. In: Biochemistry of fruit ripening (Seymour GB, Taylor JE and Tucker GA, eds.). Chapman \& Hall, London, 1-51.

Vázquez-Sánchez M, Terrazas T and Arias S (2005). Morfología y anatomía del cefalio de Cephalocereus senilis (Cactaceae) [Morphology and anatomy of the Cephalocereus senilis (Cactaceae) cactus]. An. Jard. Bot. Madr. 62: 153-161.

Wills R, McGlasson B, Graham D and Joyce D (1998). Postharvest: an introduction to the physiology and handling of fruit, vegetables and ornamentals. 4th edn. CAB International, Sidney.

Wybraniec S and Mizrahi Y (2002). Fruit flesh betacyanin pigments in Hylocereus cacti. J. Agric. Food Chem. 50: 60866089. 